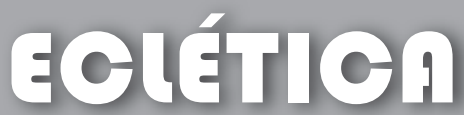 química
}

\section{ANÁLISE DE PESTICIDAS ORGANOCLORADOS EM ÓLEOS VEGETAIS POR CROMATOGRAFIA GASOSA DE ALTA RESOLUÇÃO (HRGC)}

\author{
E. B. S. Dias ${ }^{1}$. E. C. Vilela ${ }^{1}$. F. M. Lanças 2 \\ ${ }^{1}$ Instituto de Química - Universidade Federal de Goiás - CEP 740001-970- Goiânia-Go - Brasil \\ ${ }^{2}$ Instituto de Química de São Carlos - Universidade de São Paulo- CP 780-CEP 13560-590- São Carlos-SP - Brasil
}

\begin{abstract}
Resumo: Os óleos vegetais comestíveis foram introduzidos na dieta humana em substituição as gorduras animais nas últimas décadas sendo amplamente consumidos em todo o mundo.

O presente artigo descreve o desenvolvimento de uma metodologia para análise de aldrin, dieldrin, endrin e endosulfan em óleos vegetais por cromatografia gasosa de alta resolução (HRGC) utilizando-se extração em fase sólida (SPE). As médias de recuperação dos pesticidas estiveram entre 70 e $110 \%[1]$.
\end{abstract}

Palavras-chave: análise, pesticida [2], óleo, cromatografia, extração [3].

\section{Introdução}

Óleos vegetais

Composição e propriedade dos óleos vegetais

Os óleos vegetais representam uma das três maiores categorias de produtos alimentícios, além das proteínas e carboidratos. Como alimento energético o óleo fornece cerca de $9,5 \mathrm{kcal} / \mathrm{g}$, quando metabolizado no organismo humano. Ao passo que os carboidratos e proteínas apenas 4,0 $\mathrm{kcal} / \mathrm{g}$. Além do valor energético são nutrientes essenciais á dieta humana.

Consistem predominantemente de triglicerídeos os quais são ésteres do glicerol e uma classe particular de ácidos graxos. Os radicais de ácidos graxos sendo de alto peso molecular per- fazem a maior parte da molécula do triglicerídeo constituindo a parte mais reativa [4].

\section{Agrotóxicos}

A obtenção do registro para uso de agrotóxicos no Brasil é de competência do Ministério da Agricultura e da Reforma Agrária (MARA) sendo formada por três relatórios. Um relatório de eficiência agronômica que a empresa registrante submete ao MARA. Um relatório toxicológico repassado ao Ministério da Saúde (MS) para análise e publicação da respectiva monografia contendo os limites máximos de resíduos (LMR) ou, as tolerâncias e períodos de carência para as quais aquele pesticida está sendo registrado e um relatório de periculosidade ambiental que é encaminhado à Secretaria Nacional do Meio Ambiente (SENAM), onde serão avaliados os dados relativos aos aspectos ecológicos das substâncias em 
cas de seus efeitos adversos anteriormente desconhecidos [5].
Aldrin
Dieldrin
Endrin
Endosulfan
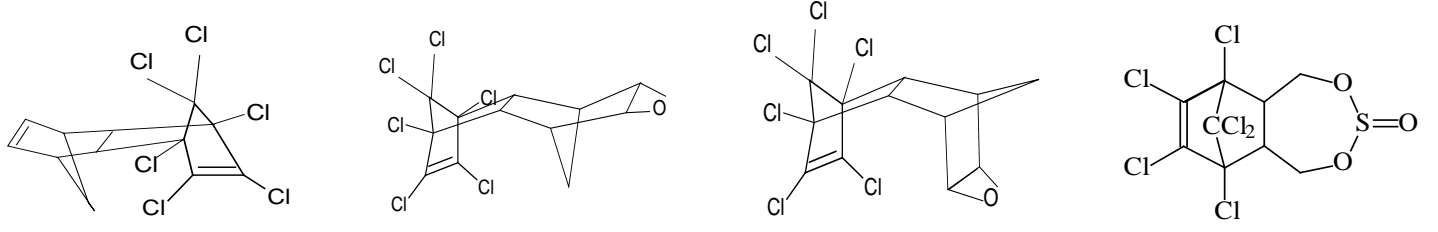

Excesso de lipides descartados

Figura 1. Estrutura química dos pesticidas em estudados

Material e Métodos

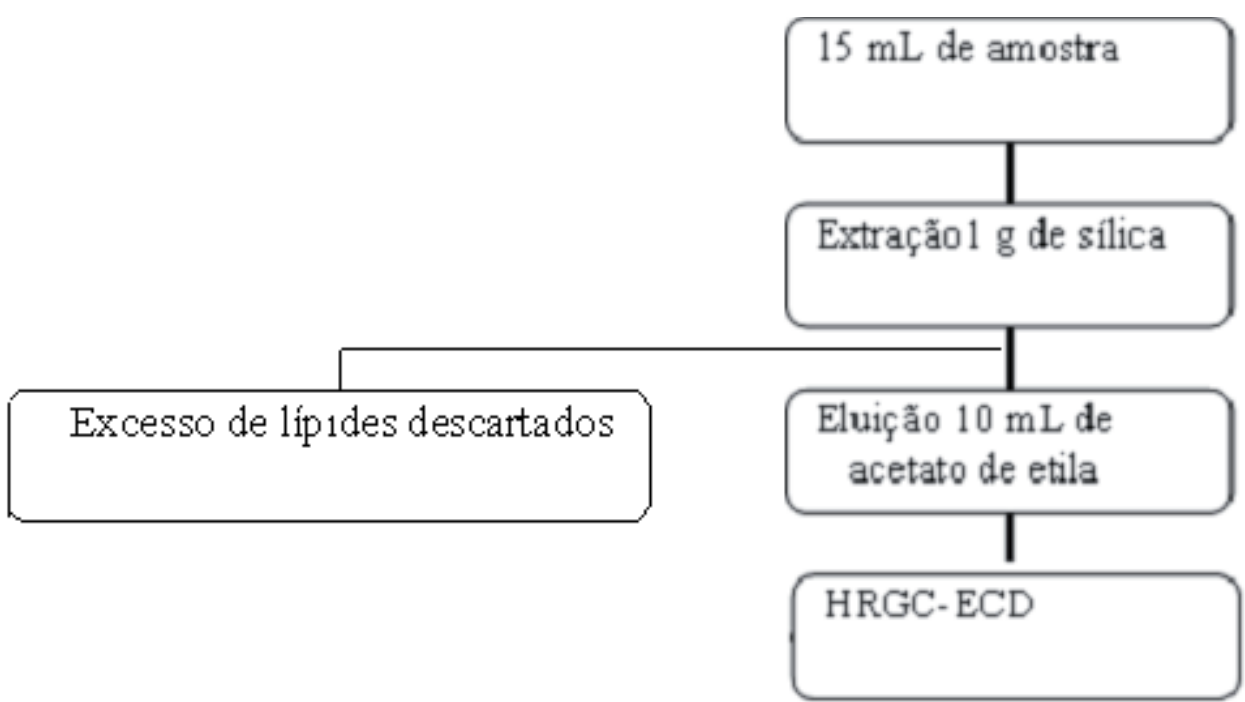

Coleta da amostras [6]

As amostras foram obtidas no comércio local da cidade de São Carlos-SP.

Reagente e soluções

Os padrões de pesticidas foram adquiridos da Polyscience Corporation. As soluções estoque a $1000 \mu \mathrm{g} / \mathrm{mL}$ foram prep

Principais equipamentos utilizados

Cromatógrafo gasoso Shimadzu GC 17A equipado com um detector de captura de elétrons e uma coluna capilar contendo como fase estacionária $5 \%$ fenil-95\% dimetil polisiloxano imobilizado $(28 \mathrm{~m} \times 0,25 \mathrm{~mm} \times 0,4 \mu \mathrm{m})$ gentilmente cedida pela L\&M. São Carlos-SP [7]

Acessórios

Seringa Hamilton de $10 \mu \mathrm{l}$ com agulha capilar. Coluna de vidro para extração em fase sólida de $20 \mathrm{~cm}$ de comprimento, $10 \mathrm{~mm}$ de diâmetro interno com torneira de teflon. Colunas pré-en-

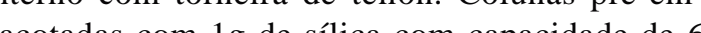
pacotadas com $1 \mathrm{~g}$ de silica com capacidade de 6
$\mathrm{~mL}[8]$.

Figura 2. Fluxograma das etapas de extração em fase sólid

\section{Resultados e discussão}

Para estabelecer o procedimento analítico para análise dos compostos de interesse estudou-se a recuperação dos pesticidas com os seguintes solventes: n-pentano, tolueno, etanol, acetato de etila, hexano e acetona [9]. Estudou-se também a viabilidade de uso de diferentes adsorventes: XAD-2 e sílica conforme as tabelas abaixo:

Tabela 1. Recuperações conseguidas das colunas empacotadas com sílica

\begin{tabular}{ccccc}
\hline Pesticidas & Aldrin & Dieldrin & Endrin & Endosulfan \\
Recuperação (\%) & 61,0 & 38,6 & 50,6 & 95,2 \\
\hline
\end{tabular}

Tabela 2. Percentagem de recuperação de pesticidas por extração em fase sólida utilizando $10 \mathrm{~g}$ de adsorvente XAD - 2.

\begin{tabular}{ccccc}
\hline \multirow{2}{*}{ Eluente } & \multicolumn{4}{c}{ Pesticidas } \\
\cline { 2 - 5 } & Aldrin & Dieldrin & Endrin & Endosulfan \\
\hline n - pentano & 28,6 & 27,5 & 23,2 & 2,1 \\
tolueno & - & - & - & - \\
Etanol & 38,8 & 33,9 & 30,1 & 0,8 \\
Somatória ( \% de recuperação) & 67,4 & 61,4 & 53,3 & 2,9 \\
\hline
\end{tabular}


Tabela 3. Recuperações de Aldrin, Dieldrin, Endrin e Endosulfan, obtidos por SPE-Si(1g), utilizando-se diferentes solventes extratores.

\begin{tabular}{|c|c|c|c|c|}
\hline \multirow{2}{*}{ Solvente Extrator } & \multicolumn{4}{|c|}{ Recuperação dos pesticidas (\%) } \\
\hline & Aldrin & Dieldrin & Endrin & Endosulfan \\
\hline Hexano & 21,6 & 30,0 & 38,8 & 8,1 \\
\hline Acetato de etila & 93,4 & 140,9 & 91,2 & 24,9 \\
\hline
\end{tabular}

Verificou-se que as recuperações quando se trabalhou com colunas pré- empacotadas estava fora da faixa recomendada pela literatura (70 a 120\%), (tabela 3). Isso ocorreu provavelmente devido a um controle inadequado da pressão aplicada ao sistema de extração em fase sólida. O trabalho realizado com colunas empacotadas no laboratório permitiu resultados ente 61 a 95\%, tabela 1 e 2[10].

A figura 3 mostra o cromatograma obtido da injeção do acetato de etila usado numa das eluições citadas.

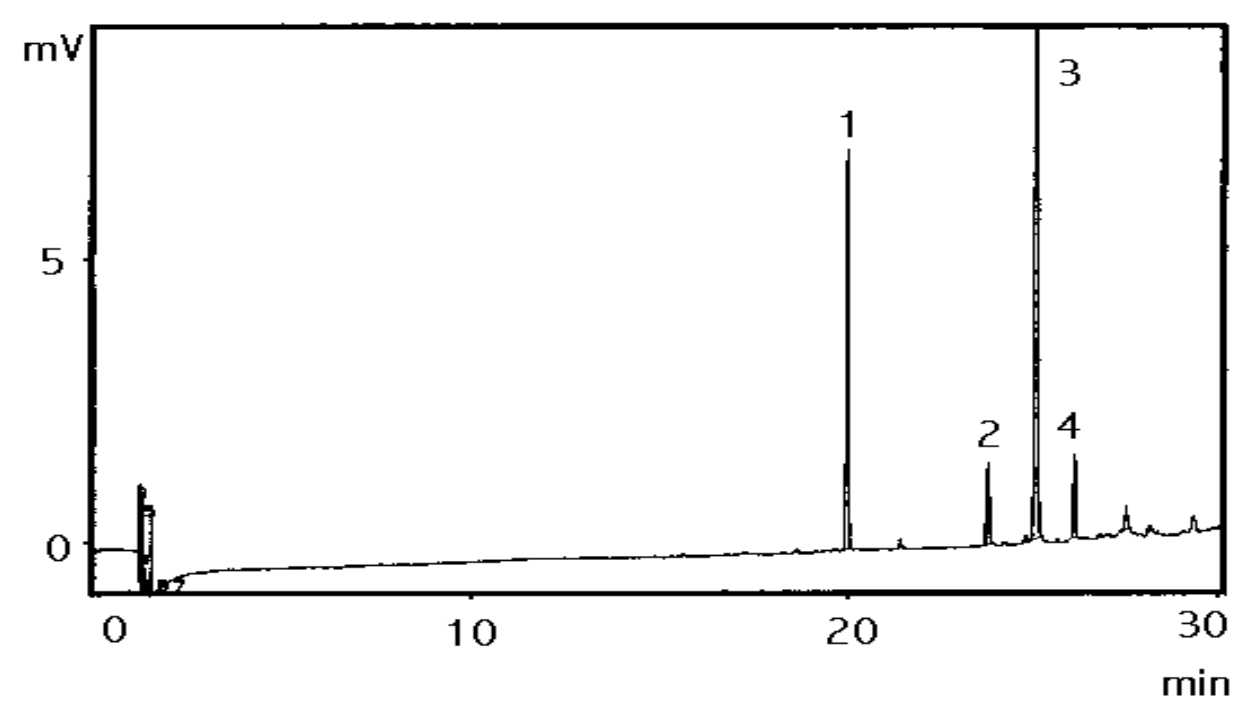

Figura 3. Cromatograma obtido da injeção de $1 \mu \mathrm{L}$ do acetato de etila obtido da coluna com 1g de sílica. A ordem de eluição dos compostos é: 1Aldrin, 2 Endosulfan, 3 Dieldrin, 4 Endrin.

\section{Conclusões}

O método proposto é relativamente simples de fácil operação e custo mais baixo do que as metodologias de extração líquido-líquido, por exemplo. Pode ser economicamente interessante também por reduzir os resíduos químicos gerados no laboratório. O procedimento pode ser testado para outras matrizes oleosas.

\section{Agradecimentos}

E. B. S. Dias agradece à Coordenação de Aperfeiçoamento de Pessoal de Nível Superior pela bolsa de mestrado concedida.

E. B. S. Dias, E. C. Vilela, F. M. Lanças. Analysis of Organochlorine Pesticides in Vegetable Oils by High Resolution Gas Chromatography (HRGC)
Abstract: Vegetable oil were introduced in human diet in the last decade to change the use of animal fats. The chemical products althrought utilized in correct manner can cause residues in food bring to healt there be a necessity of a constant monitoring of the concentration level the several agricultural products. The answer to this necessity has motivated the development of several of a methodology for simultaneous analysis of aldrin, dieldrin, endrin and endosulfan in vegetable oils by HRGC, using solid phase extraction (SPE) using silica and XAD-2. The recovery was $70-110 \%$

\section{Keywords: analysis, pesticide, oil, chromatography, extraction}

\section{Referências}

1] H.W.Lawson. Standards Fo fats \& Oil. 2ed Wesport, (1985) 30 .

2] A. S. Y CHAU. B. K AFGHAM. Analysis of Pesticides in Waters, CRC Press. Inc. (1) (1982).

3] S. M. BRANCO, O Meio Ambiente em Debate, Ed Moderna, 14å. ed, São Paulo, Brasil, (1988).

[4] F. A. Norris. Extraction of fats and oils. In: SWERN, D, ed. Bailley`s Industrial Oil and Fat Products. 4 ed, New York, (1979).15.

5] W. H. Lara. G. C. BATISTA. Pesticidas. Química Nova, 15(2). (1992), 161.

6] D. L WATSON. and A. W BROWN. Pesticides Management and Inseticide Resistance, Academic Press, New York, (1977).

7] F. M. LANCCAS. Cromatografia em fase gasosa; Rev. Quím. Ind., 55(1986), 12.

8] M. SUZUKI; Y. YAMATO and T. WATANABE.Analysis of environmental samples for organochlorine insecticides and relates compounds by high-resolution electron capture gas chromatography with glass capillary columns; Environ. Sci. Technol. 11 (1977), 1109

9] J. SHERMA. Pesticides, Anal. Chem., 65 (1993), 40. [10] T. WHERNER and J. N SEIBER. J. High Resolut. Chromatogr. 4(1981), 348. 